\title{
Analysis of potato crisp colour topography following infection by 'Candidatus Liberibacter solanacearum'
}

\author{
S.L. Lewthwaite ${ }^{1}$, T. Holmes ${ }^{2}$ and C.M. Triggs ${ }^{3}$ \\ ${ }^{1}$ Plant \& Food Research Limited, Cronin Road, RD1, Pukekohe 2676, New Zealand \\ ${ }^{2}$ Plant E Food Research Limited, Private Bag 92169, Auckland 1142, New Zealand \\ ${ }^{3}$ University of Auckland, Private Bag 92019, Auckland 1142, New Zealand \\ Corresponding author: Steve.Lewthwaite@plantandfood.co.nz
}

The potato (Solanum tuberosum L.) is classified as an herbaceous perennial because of the clonal continuity provided by its primary carbohydrate storage organ, the tuber. The biochemical composition of the tuber varies throughout its development and during postharvest storage, but consists principally of water and carbohydrates. Although sugars make only a small contribution to the total carbohydrate content, they are critical to the quality of fried potato products. Increased concentrations of the reducing sugars glucose and fructose contribute to the Maillard reaction, which promotes dark colours and burnt flavours. These sugars are also key precursors for acrylamide formation, with associated consumer health concerns. The concentrations of specific sugars within a potato tuber are a function of the cultivar, tuber health and maturity, the growing environment and storage conditions. While the general colour of processed potato crisps may be readily assessed on a subjective visual scale or by reflectance spectrophotometer, infection by the bacterium 'Candidatus Liberibacter solanacearum' causes highly uneven colouration across individual crisp surfaces. This research explores the use of image analysis to define disease symptom expression in processed crisps from infected plants.

\section{Tomato potato psyllid (Bactericera cockerelli Sulc.) impacts on taewa seed quality and performance: preliminary results}

\author{
A.J. Puketapu and R. Gardner-Gee \\ The New Zealand Institute for Plant \& Food Research Limited, Mt Albert Research Centre, 120 Mt \\ Albert Rd, Sandringham, Auckland 1025, New Zealand \\ Corresponding author: aleise.puketapu@plantandfood.co.nz
}

Taewa (Solanum tuberosum L., Maori potatoes) are susceptible to tomato potato psyllid (Bactericera cockerelli Sulc., TPP) infestation and to infection with the bacterium Candidatus Liberibacter solanacearum (Lso) vectored by the psyllid. Current growing systems used by taewa growers leave the crop highly vulnerable to TPP and Lso infection, leading to potential reductions in seed tuber quality and harvestable yield. Seed tubers for two virus-free taewa lines ('Moemoe' and 'Tutaekuri') grown under high (calendar spraying of insecticides) and low (reduced insecticide spray regime) levels of TPP protection in a zebra chip small plot trial during 2011/12 in Pukekohe were stored after harvest. Tubers were later sorted into two seed size categories, small $(<40 \mathrm{~g})$ and large (40-74 g), and planted in the field in the 2012/13 growing season. A subsample of tubers from each treatment and seed size combination were submitted for Lso testing. The results indicated that the larger seed tuber size and the higher level of TPP protection increased yield for 'Moemoe'. Trends for 'Tutaekuri' were less clear. 